\section{Los derechos como resultado de luchas históricas ${ }^{1}$}

\section{Elizabeth Jelin}

Docente del Programa de Doctorado en Ciencias Sociales.

Universidad Nacional de General Sarmiento.

Investigadora Superior del CONICET con sede en el Instituto

de Desarrollo Económico y Social de Buenos Aires.
Construir ciudadanía /

Perspectivas
Habitualmente escuchamos hablar de "derechos humanos" y de "ciudadanía". Es común que distintas personas en diferentes contextos y circunstancias hagan alusión a ellos, y es común que el significado de estos términos varíe en los diversos usos que reciben: "todos tenemos derecho a expresarnos", "el derecho a una vida digna tiene que ser universal", "las dictaduras violan los derechos humanos básicos". Incluso se justifican guerras e invasiones en nombre de la democracia y los derechos humanos. En el caso de "ciudadanía", la diversidad de usos es igualmente amplia. Políticos y dirigentes suelen hablarle a "la ciudadanía" y en numerosas situaciones oímos acerca de nuestros "deberes como ciudadanos". Al entrar y salir del país y al hacer trámites administrativos o jurídicos debemos llenar formularios declarando nuestra "ciudadanía".

En la actualidad, a partir de la Declaración Universal de los Derechos
Humanos de 1948, y de todos los pactos, tratados y convenciones internacionales posteriores, el campo de la discusión y defensa de esos derechos humanos es amplio y complejo. Los documentos y tratados están anclados en un principio ético universal en torno a los atributos que hacen a la condición humana, con sus aspectos tangibles (alimentación, salud) e intangibles (dignidad, libertad, igualdad, cultura), que merecen ser defendidos y protegidos. Estos acuerdos (siempre parciales y cuestionados) no son eternos. Son el producto de luchas históricas, de conquistas logradas por hombres y mujeres que, en contextos históricos específicos, se han preocupado y ocupado por lograr que las instituciones reconozcan y especifiquen los atributos humanos que deben ser garantizados, y por quienes han luchado por ampliar el acceso a estos atributos a más y más categorías de seres humanos, previamente
1) Este capítulo forma parte del libro: Jelin, Elizabeth, Caggiano, Sergio y Mombello, Laura: Por los derechos.
Hombres y mujeres en la acción colectiva. Editorial Nueva Trilce. Buenos Aires, 2011.

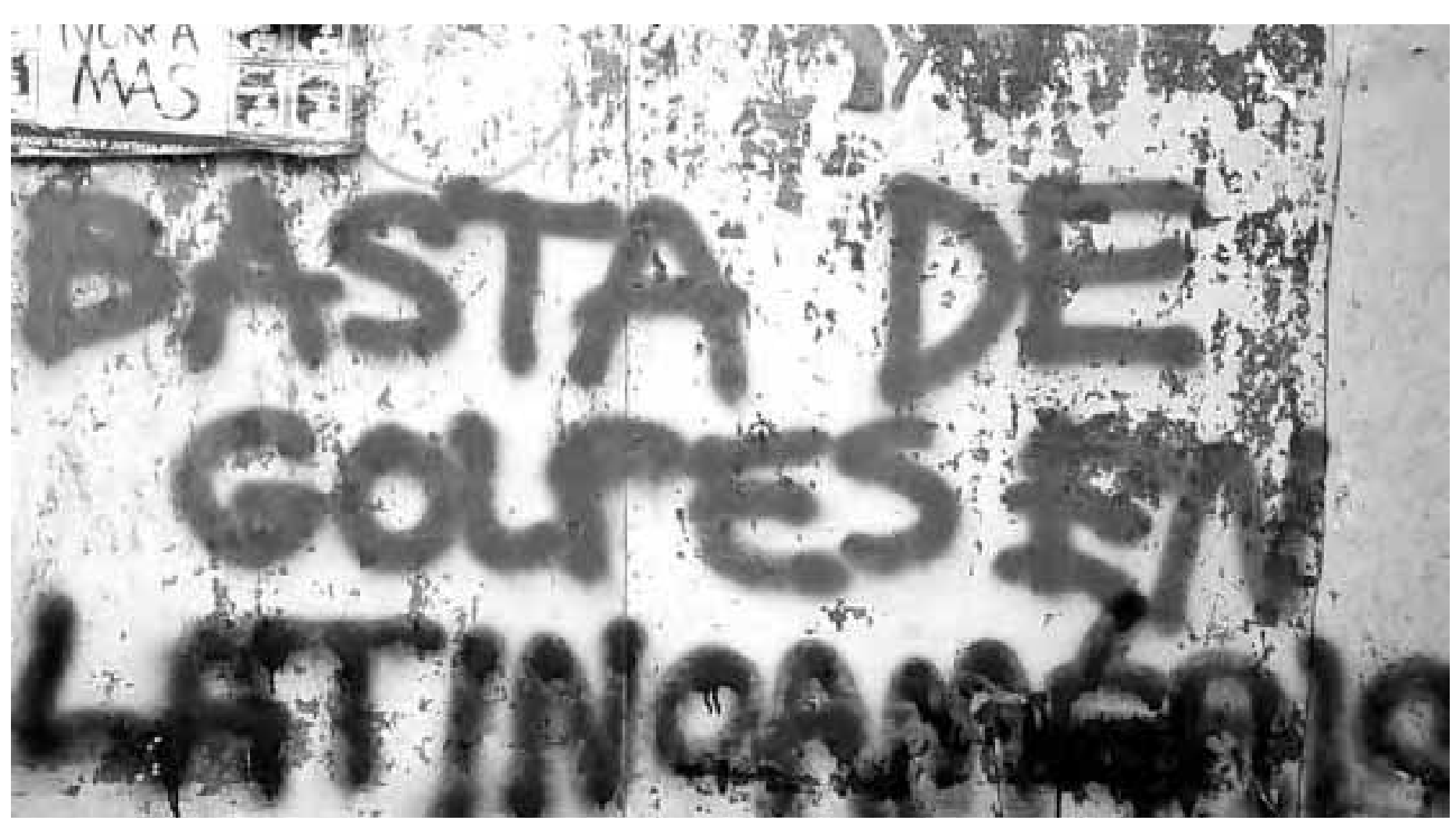


discriminados y excluidos en función de su género, raza, edad, etnicidad, educación, etcétera.

Si en el plano de la humanidad global hablamos de "derechos humanos universales", esto se traduce en acciones humanas en distintas escalas, precisamente desde el plano global hasta las comunidades locales, pasando por el Estado nacional, nivel en el que se define la ciudadanía en el mundo contemporáneo.

\section{1. ¿Qué es la ciudadanía?}

En la teoría democrática, la noción de ciudadanía está anclada en la definición legal de derechos y obligaciones que la constituyen. Hay tres ejes claves de debate ideológico, teórico y político: la naturaleza de los "sujetos" que serán considerados ciudadanos, el contenido de sus "derechos", y las responsabilidades y compromisos inherentes a la relación ciudadanía-Estado (Jelin, 1996). Históricamente, el tema de los derechos humanos y de la ciudadanía se inaugura en Occidente como una demanda de la modernidad, específicamente de la burguesía (y de sus filósofos) frente al poder y los privilegios de las monarquías. Desde allí, la historia es larga y compleja en lo referente a la lucha tanto política como por las ideas. Las luchas históricas concretas han estado y siguen vigentes en relación con el contenido de derechos específicos, sea el derecho al voto, los beneficios sociales del Estado de Bienestar o la educación pública en lenguas vernáculas. Los análisis históricos y comparativos, en esta línea, se preocupan por explicar la variación en los contenidos de la ciudadanía. El clásico en el tema es T.H. Marshall, quien muestra la interconexión entre el desarrollo del Estado-nación inglés y la ampliación de los derechos de ciudadanía. Marshall plantea una progresión histórica que implica, primero, la extensión de los derechos civiles, luego una segunda etapa de expansión de los derechos políticos y, finalmente, los derechos sociales. ${ }^{2}$

En esta visión, por ejemplo, el desarrollo del aparato del Estado de Bienestar es la cara estatal del proceso de expansión de los derechos económico-sociales de los ciudadanos (Marshall, 1964; Offe, 1985; Lefort, 1987). Estas cuestiones generales han sido, y siguen siendo, el eje de los debates y luchas sociales concretas en cuanto a la definición (formal) del/a ciudadano/a dentro de los países —o sea, el establecimiento de los límites sociales entre los/ as incluidos/as y excluidos/as, sean éstos/as "extranjeros/as", marginados/as o discriminados/as por alguna razón especial (de propiedad, educación, raza, género, o cultura).

El debate y la lucha son también sobre los contenidos a los cuales los/as ciudadanos/as incluidos/as pueden acceder, es decir, cuáles son sus derechos. En el plano internacional, a su vez, la defensa de los derechos humanos toca y requiere la reformulación de la idea de soberanía nacional. La ampliación de la base social de la ciudadanía (por ejemplo, la extensión del voto a mujeres o a analfabetos/ as), la inclusión de grupos sociales minoritarios, discriminados o desposeídos como miembros de la ciudadanía y el reclamo por la "igualdad frente a la ley" han sido temas casi permanentes en la historia contemporánea. Las manifestaciones internacionalmente más visibles y conocidas de estas luchas sociales son las que atañen a la "solución final" del nazismo, el movimiento de derechos civiles en los Estados Unidos en la década de los sesenta, las que se llevaron a cabo contra el Apartheid en África del Sur, las reivindicaciones del feminismo para acabar con todas las formas de discriminación de las mujeres, los reclamos de ciudadanía de grupos étnicos minoritarios y de los pueblos originarios. La ciudadanía puede ser encarada también en un plano más abstracto y general. En efecto, desde una perspectiva analítica, el concepto de ciudadanía hace referencia a una práctica conflictiva vinculada al poder, que refleja las luchas acerca de quiénes podrán decir qué en el proceso de definir cuáles son los problemas comunes y cómo serán abordados (Van Gunsteren, 1978). En este sentido, tanto la ciudadanía como los derechos están siempre en proceso de construcción y de cambio. Esta perspectiva implica partir de una premisa: el derecho básico es "el derecho a tener derechos" (Arendt, 1973; Lefort, 1987). En esto, la acción ciudadana es concebida en términos de sus cualidades de automantenimiento y expansión: "las acciones propias de los ciudadanos son sólo aquellas que tienden a mantener, y de ser posible a incrementar, el ejercicio futuro de la ciudadanía" (Van Gunsteren, 1978:27; Lechner, 1986). Lo importante de la tradición de los derechos humanos occidentales es la ausencia de referentes trascendentes. Al no contar con poderes últimos ni referentes sobrehumanos, no hay autoridad por encima de la sociedad, no hay un "gran juez" para dirimir los conflictos. Por lo tanto, la justicia queda anclada en la existencia de un espacio público de debate, y la participación en la esfera pública se convierte en un derecho y en un deber. Esta perspectiva autorreferida de las nociones de derechos y de ciudadanía tiene consecuencias importantes para
2) La hipótesis histórica de la expansión de los derechos expuesta por Marshall se corresponde con la terminología utilizada en el ámbito de Naciones Unidas, donde se habla de generaciones de derechos. Los derechos de primera generación son fundamentalmente los derechos civiles y políticos; los de segunda generación son los derechos económicos, sociales y culturales, que requieren un papel activo del Estado para asegurar las condiciones materiales necesarias para el ejercicio de los anteriores. Estos dos tipos se refieren fundamentalmente a derechos indiviuales. Los derechos de tercera generación (paz, desarrollo, medio ambiente) y de cuarta generación (derechos de los pueblos) son de otra naturaleza, ya que hacen referencia a fenómenos globales y colectivos. Es importante señalar que esta ordenación se refiere a la historia de la discusión dentro de los organismos internacionales, y no debe interpretarse en términos de prioridades o de un desarrollo histórico necesario. De hecho, no se trata de una regla histórica universal. Así, el desarrollo de los derechos de ciudadanía social a través del Estado de Bienestar, más que complementar o expandir los derechos civiles, puede llegar a reemplazar el ideal del ciudadano responsable por la realidad del "cliente" (Habermas, 1975), convirtiéndose en una forma de boicot al mismo desarrollo de un sentido pleno del ciudadano/a como sujeto de derechos. 
la práctica de la lucha contra las discriminaciones y las opresiones: el contenido de las reivindicaciones, las prioridades políticas, los ámbitos de lucha pueden variar, siempre y cuando se reafirme el derecho a tener derechos y el derecho al debate público del contenido de normas y leyes. Lo relevante y significativo de esta historia es que, al pasar del individualismo abstracto de la teoría liberal a las condiciones históricas específicas, la noción de "individuo" con derecho a participar en el debate público se definió en términos excluyentes - "hombres" como equivalente a hombres masculinos (Scott, 1996). ${ }^{3}$

Además de la referencia a los derechos, la ciudadanía comprende las responsabilidades y los deberes de los/as ciudadanos/as. El deber tiene un imperativo coercitivo; las responsabilidades son más amplias y superan el campo de la obligación. Incluyen el compromiso cívico, centrado en la participación activa en el proceso público (las responsabilidades de la ciudadanía) y los aspectos simbólicos y éticos, anclados en inclinaciones subjetivas que confieren un sentido de identidad y de pertenencia a una colectividad, un sentido de comunidad. $\mathrm{O}$ sea, aquello que promueve la conciencia de ser un sujeto con derecho a tener derechos. Esta dimensión cívica de la ciudadanía está anclada en los sentimientos que unen o atan a una colectividad (y contrasta con los elementos aparentemente más racionales o aun instrumentales de los derechos de la ciudadanía civil y social) (Kelly, 1979; Reis, 1993).

En el plano macrosocial, el proceso de construcción de derechos y deberes ciudadanos tiene como referente al Estado, corporizado en aparatos institucionales tales como el jurídico, el Poder Legislativo y las instituciones de bienestar. Sin embargo, ningún mecanismo de la democracia formal puede asegurar que estas instituciones sean efectivamente depositarias de una representación ciudadana plena e igualitaria. De hecho, la historia latinoamericana ha sido y es la de una lucha por transformar un Estado que lejano respecto de la ciudadanía, apropiado por algunos y alejado de muchos/as. Esto implica que el reconocimiento de las instituciones estatales y su legitimidad por parte de los "sujetos de derecho" es un largo proceso histórico de luchas sociales, sin garantía de un final necesariamente "feliz" y armónico. El proceso de democratización involucra la (re)construcción de las instituciones del Estado y la transformación de las instituciones de la sociedad civil. Supone el desmantelamiento de formas antidemocráticas de ejercicio del poder (autoritarias, corporativas y/o basadas en la pura fuerza) y también un cambio en las reglas que gobiernan la distribución del poder, el reconocimiento y la vigencia de los derechos, así como los criterios que otorgan legitimidad a los actores sociales. La gente tiene que adoptar comportamientos y creencias adecuadas o coherentes con la noción de democracia, aprender a actuar dentro del renovado sistema institucional. Y los líderes políticos y las clases dominantes deben aprender a reconocer y tomar en cuenta los derechos y las identidades de actores sociales diversos y renunciar a la arbitrariedad y a la impunidad.

La construcción de la institucionalidad democrática es un desafío a la capacidad de la ciudadanía y las organizaciones de la sociedad civil para promover la transformación del Estado. Corresponde a los actores de la sociedad la difícil tarea de demandar, empujar, promover y "policiar" ese proceso, cuando al mismo tiempo, y de manera especular, se aprende y construye ciudadanía. La creación de contextos institucionales democráticos puede llegar a ser, entonces, resultado y a la vez estímulo para el fortalecimiento de una cultura de la ciudadanía democrática.

El concepto de "ciudadanía" es histórico y dinámico. Puede definirse como un conjunto de derechos y responsabilidades que las personas tienen en el marco de una comunidad determinada y en tanto miembros de esta comunidad. Implica que cada persona debe ser tratada como miembro pleno de una sociedad de iguales, y esto requiere el otorgamiento de derechos de ciudadanía independientemente de cualquier otra característica suya. Es común hablar de la ciudadanía en términos de derechos civiles, políticos, sociales y culturales. Entre los derechos civiles garantizados encontramos la libertad de palabra, de pensamiento, de religión, de asociación, de propiedad, de contrato, de circulación. Suponen la igualdad de los/as ciudadanos/as ante la ley, aunque se reconocen diferencias según la edad. Los derechos políticos garantizan la participación en la vida pública y el sufragio, y dan a las personas la posibilidad de elegir y de ser elegidas como representantes. La ciudadanía social otorga a los sujetos el derecho al bienestar general, a un nivel adecuado de educación y de salud, al trabajo, a la vivienda y a la seguridad social. Finalmente, la ciudadanía cultural otorga a los grupos o colectivos sociales el derecho a vivir de acuerdo con su propio estilo de vida. Estas definiciones son formales y legales. Sin embargo, normalmente existe una enorme distancia entre la formalidad de la ley y la realidad de su aplicación (esto es, entre lo que la ley dice y lo que se hace), y una buena parte de las luchas sociales está históricamente destinada a acortar esta brecha. Puede también haber una gran distancia entre la formalidad de la ley y la conciencia sobre los derechos que los propios sujetos de derecho tienen (o sea, entre lo que la ley dice y lo que los/as ciudadanos/ as piensan o sienten). En consecuencia, aun en los casos en que existen derechos de ciudadanía formalmente definidos, en la vida cotidiana la gente no los ejerce, no los demanda, no los actúa, no se apropia de ellos. De esta forma, se viven como "normales" y "naturales" las jerarquías y desigualdades sociales.

Por esta razón, una pregunta central es saber cómo se construye 
ciudadanía "desde abajo". En otras palabras, lo que importa son las maneras en que se van ampliando las categorías de personas que son consideradas ciudadanos/as (por ejemplo, reconocer que quienes son analfabetos/as también son ciudadanos/as con derechos) y cómo se van adquiriendo más derechos. También importa el modo en que quienes formalmente son definidos/as como ciudadanos/as llevan adelante las prácticas correspondientes a esa condición: ¿en qué espacios o ámbitos se ejercen efectivamente nuestros derechos ciudadanos? ¿En cuáles relaciones sociales? ¿Frente a qué instituciones? ¿En relación con qué demandas e intereses? Los escenarios de la acción pública y del reclamo y la lucha por derechos son múltiples y se ubican en diversas escalas o niveles. Correlativamente, en la sociedad hay una pluralidad de órdenes normativos que operan al mismo tiempo. Hay, por ejemplo, tribunales internacionales que juzgan los crímenes de lesa humanidad o códigos internacionales que procuran reglamentar el comercio mundial, y hay también normas y leyes propias de cada país o de cada provincia establecidas en sus constituciones y otros instrumentos normativos. Los grupos que luchan por conseguir un derecho o por proteger uno ya existente se mueven en estas escalas y respecto de esta pluralidad de órdenes normativos. Organizaciones transnacionales, por ejemplo, desarrollan su acción en contra de la contaminación ambiental a nivel global mientras que las comunidades indígenas que luchan por el reconocimiento de sus derechos sobre la tierra que habitan lo hacen en una escala local o nacional. No obstante, suelen darse casos en que la defensa ambiental de un determinado territorio se combina y se une con el reclamo que una comunidad hace contra una empresa transnacional que ocupa las tierras donde aquélla está asentada y contamina el aire y los ríos de la región. Es común que en estos casos las organizaciones y grupos que reclaman (y los que resisten esos reclamos) formen alianzas y articulen sus intereses. Es claro que entonces el conflicto puede desarrollarse en varias escalas a la vez. No es acertado pensar esta multiplicidad de sentidos y de niveles como si se tratara de esferas cerradas, separadas entre sí. Para comprender la coexistencia de sentidos y niveles debemos ser capaces de advertir las mezclas entre ellos y cómo, a veces, los intereses y escenarios de acción se articulan en distintas escalas de manera armónica o conflictiva. En suma, esta perspectiva de las nociones de derecho y de ciudadanía tiene consecuencias importantes para la práctica de la lucha contra las discriminaciones y las opresiones: el contenido de las reivindicaciones, las prioridades políticas, los ámbitos de lucha pueden variar, siempre y cuando se reafirme el derecho a tener derechos y el derecho al debate público del contenido de las normas y las leyes. Tanto la ciudadanía como los derechos están siempre en proceso de construcción y de cambio.

\section{Un proceso con idas y vueltas}

El proceso dinámico de construcción de derechos y de ciudadanía toma formas diversas. La ampliación y profundización de los mismos puede darse a través de su institucionalización. Por ejemplo, si hoy en día la existencia de los sindicatos nos resulta "natural" es porque más de cien años atrás los/as trabajadores/as lucharon por el derecho a defender conjuntamente sus intereses reuniéndose en sindicatos hasta entonces inexistentes. La ampliación y la profundización pueden darse también de formas menos institucionalizadas pero no menos importantes. La crítica social del feminismo, entre otras cuestiones, ha logrado ocupar en nuestros días un lugar en la agenda académica, política y mediática que era impensado hace cuarenta años, y muchas de sus demandas son parte de debates habituales en diferentes espacios sociales (aunque igualmente es cierto que muchas de esas demandas todavía no están incorporadas en las normas jurídicas del país).

Pero no es sólo de éxitos, ampliaciones y profundizaciones que está hecha la dinámica de este proceso. Derechos por los que se luchó y que se conquistaron hace mucho tiempo fueron desmantelados después; discusiones que avanzaron en un plano pudieron haber generado retrocesos en otros, etcétera.

\section{Tensiones y dilemas}

El proceso de demanda, consolidación y mantenimiento de derechos humanos y de ciudadanía genera tensiones o dilemas. Algunos de ellos son constitutivos, es decir, forman necesariamente parte de este proceso. No pueden ser resueltos de manera abstracta sino a partir de casos concretos.

En primer lugar, somos "sujetos de derecho" en relación con una colectividad o una comunidad política a la que pertenecemos (generalmente el Estado-nación y, en última instancia, la comunidad humana). Es esta colectividad la que teóricamente garantiza los derechos. Pero como parte de esa colectividad de pertenencia también tenemos responsabilidades que implican participar activamente en el sostenimiento del espacio de cuidado, respeto y autonomía de ese "nosotros/as" del que formamos parte. Esto es, se trata del compromiso cívico con la colectividad, basado en el sentido de identidad y de pertenencia que es, a su vez, lo que da conciencia de ser un sujeto de derecho. La tensión entre derechos y responsabilidades o deberes de ciudadanía es permanente, con contenidos cambiantes.

En segundo lugar, los derechos humanos son universales, afectan a todos/as; la ciudadanía es también universal aunque limitada: afecta a todos los miembros de un Estado-nación. ¿Significa esto que los derechos humanos y los de ciudadanía necesariamente igualan o tienen como horizonte la igualdad? El ejercicio de la ciudadanía y los derechos, ¿es siempre realizado de la misma manera, para todos y todas? Hay diferencias entre las personas y muchas veces los reclamos por derechos son reclamos de reconocimiento, de respeto o de tolerancia de las diferencias: un grupo pide que se le respete una costumbre religiosa; un sector social, que se acepte la legitimidad de determinado gusto $o$ elección que por alguna razón no ha sido considerado legítimo 


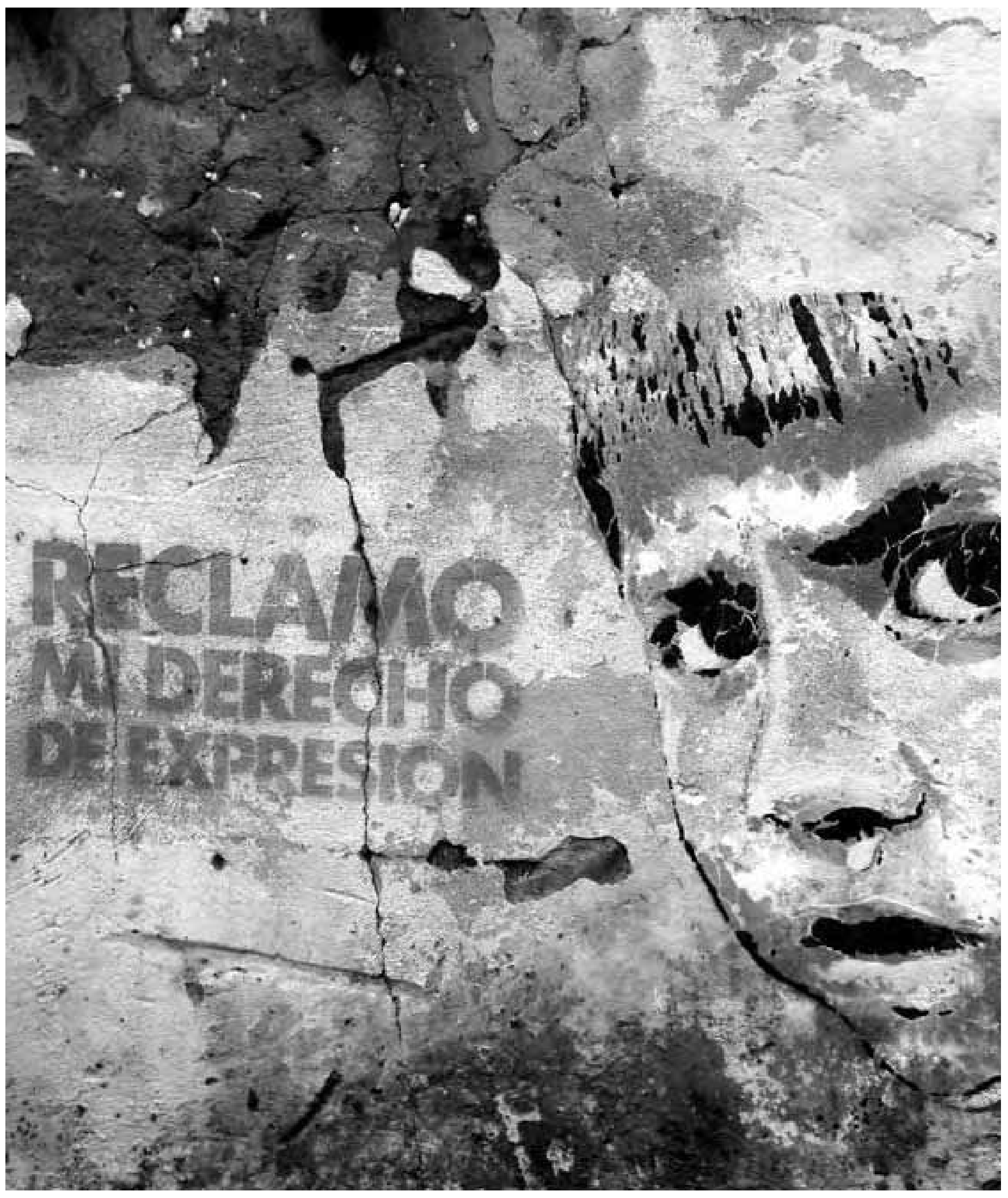


hasta ese momento, etc. ¿Cómo entender las diferencias en el campo de los derechos humanos y de la ciudadanía?

Hay distintas maneras de encarar el tema. En una primera perspectiva, la diferencia puede ser concebida como inherente a algunas personas. En esta mirada, la diferencia suele convertirse en sinónimo de inferioridad y entonces las personas diferentes son vistas como "dependientes" o como "no ciudadanas". Las demandas sociales enarboladas por los/as "diferentes" (inferiores) comenzaron siendo un reclamo de igualdad. La población negra en los Estados Unidos en la segunda mitad del siglo XX reclamaba, por ejemplo, poder comprar en los mismos comercios o viajar en el mismo transporte público que la población blanca. Por otra parte, las mujeres venían reclamando desde fines del siglo XVIII por su derecho al voto, que les fue otorgado en la mayoría de los países recién durante los años 1930-1950. Más tarde, reclamaron por el acceso a lugares y posiciones antes vetadas (desde clubes exclusivos hasta ocupaciones tradicionalmente masculinas).

Sin embargo, la igualdad literalmente entendida puede ser engañosa o insuficiente en muchas situaciones. En el caso del embarazo y la maternidad de una mujer trabajadora, ¿se requiere igualdad -es decir, negar la diferencia entre hombres y mujereso un tratamiento "especial", como es el otorgamiento de licencias laborales específicas? O, para llevar el tema a otro campo, ¿qué podría significar igualdad de derechos en la educación de un chico discapacitado? ¿Su educación debe ser igual (en el sentido de "la misma") que la del resto de los niños y niñas?

El énfasis en la norma de la igualdad refuerza una concepción basada en el derecho universal natural que reafirma que todos los seres humanos son iguales por naturaleza. Pero los seres humanos no son sólo "naturales" sino sociales e históricos, esto es, son lo que son en tanto parte de una sociedad o de un grupo social y tienen una historia. En esa otra cara de la realidad, los individuos no somos todos iguales; la vida social y la historia nos hacen diferentes a unos/as de otras/os. Entender la igualdad como norma abstracta puede llevar a una formalización excesiva de los derechos, aislándolos de las estructuras sociales concretas en que existen y cobran sentido. Igualdad y diferencia están en permanente tensión.

Otra crítica a la noción de igualdad está contenida en la universalidad de los derechos humanos o de la ciudadanía. Esta crítica la expresan intelectuales y activistas que defienden los intereses de diversos grupos o sectores sociales subordinados (feministas, intelectuales de ex colonias o países del tercer mundo, etc.), desde la segunda mitad del siglo XX y en lo que va del XXI. Lo que esta crítica señala es que, cuando se habla de una perspectiva "universal", en realidad se lo hace desde los valores del hombre (varón) blanco, occidental, adulto, etc. Es decir que lo universal tiene un punto de referencia muy particular para pretenderse como tal. El problema no es la búsqueda de la igualdad universal, sino que la misma olvida que cada quien habla desde un lugar social específico y que nadie puede tener una mirada universal. Dicho en otros términos, el tratamiento igualitario requiere que todas las personas se midan de acuerdo con las mismas normas, pero en realidad no existen normas de conducta y de cumplimiento "neutrales" o "naturales". La formulación de leyes y reglas tenderá a estar sesgada en favor de los grupos privilegiados, dado que es su experiencia particular la que configura implícitamente la norma que se pretende universal. En consecuencia, en tanto existan diferencias grupales en capacidades, socialización, valores y estilos cognitivos y culturales, sólo tomando en cuenta dichas diferencias se podrá lograr la inclusión y participación de todos y todas en las instituciones económicas y políticas. La conclusión es clara: no es posible formular derechos y reglas en términos universales que sean ciegos a las diferencias.

La historia de las luchas y reivindicaciones por la ampliación de los derechos va y viene entre la igualdad y la diferencia. Las reivindicaciones planteadas en términos de derechos remiten a un paradigma de la igualdad pero, al mismo tiempo, las diferencias existen y muchas veces es necesario reclamar para que se las respete. Se hace difícil, por lo tanto, mantener aquel paradigma de la igualdad universal. La búsqueda universal e igualitaria de los derechos ha sido efectiva políticamente puesto que permite combatir formas de discriminación y poner límites al poder. Hablar de "igualdad natural" ha servido para recordar que no hay "inferiores por naturaleza" pero, a la vez, siendo iguales por naturaleza somos diferentes por sociedad, por cultura, por historia. Entonces, ¿simplemente se trata de reivindicar la diferencia? Esto tiene sus riesgos, ya que las diferencias son muchas veces sinónimo de desigualdades y falta de oportunidades. ¿Y cómo luchar contra las diferencias que son desigualdades? Sin duda, el problema es complejo en un espacio contradictorio y paradójico en el que conviven el reclamo de derechos iguales y por un tratamiento igualitario, por un lado, y el derecho a un tratamiento diferenciado y a la valorización de las especificidades de cada categoría o grupo social, por el otro. No hay una salida fácil y sencilla sino una tensión inevitable entre el principio de la igualdad y el derecho a la diferencia. Pero esta tensión puede ser productiva. Reconocerla tiene un beneficio importante porque estimula el debate y la creatividad, ayuda a evitar los dogmatismos y a superar las injusticias y desigualdades.

Asimismo, existe otro tema altamente controvertido vinculado a la pertenencia y al reconocimiento de bienes simbólicos, del derecho a tener una identidad colectiva, de pertenecer a una comunidad, de defender intereses o tener reivindicaciones en función de ella. Nosotros pertenecemos al género humano y a la vez a comunidades específicas. En este sentido, las comunidades y las culturas, en su diversidad, son los ingredientes básicos de la humanidad y dan sentido y contenido al principio 
abstracto de la igualdad. El tema de la pertenencia comunitaria se vuelve problemático cuando hay una comunidad hegemónica (normalmente un Estado-nación) que engloba a otra (y que incluso puede pretender ignorarla o borrarla étnica o culturalmente). Esta cuestión aparece como urgencia política cuando entra en juego el reconocimiento del pluralismo cultural. Hablar de derechos culturales es referirse al derecho de grupos, comunidades, colectivos o sociedades (autodefinidas como tales) a vivir conforme a su propio estilo de vida, a hablar su propio idioma, usar su vestimenta y a conseguir el reconocimiento y un trato justo de parte de las leyes del Estado-nación en que les toca vivir (y en relación con el cual suele llamárselos "minorías"). Pero no se trata únicamente de derechos culturales. También suelen perseguirse objetivos económicos y políticos en función de la pertenencia a grupos y comunidades dentro de un Estado-nación.

Estos intereses, demandas y derechos, plantean una nueva tensión: los derechos humanos individuales pueden llegar a ser contradictorios con los derechos colectivos. La vigencia de los derechos humanos universales no es garantía de la vigencia de los derechos colectivos de los pueblos y, viceversa, el derecho de un pueblo a vivir su propio estilo de vida puede basarse en la negación de derechos humanos básicos y en la crueldad para ciertas categorías sociales dentro de esa cultura. Éste es el tema del relativismo cultural y el respeto a las diferencias. Pensar una agenda de derechos étnicos, derechos de minorías o de grupos sociales específicos implica una profunda revisión de la noción original de los derechos humanos, concebidos desde un principio de manera abstracta y privilegiando la universalidad y los sujetos individuales por fuera de cualquier pertenencia colectiva. El planteo de los derechos de los pueblos indígenas y de las minorías, por ejemplo, supone colocar en primer plano que el concepto de derechos humanos sólo adquiere sentido en circunstancias culturales específicas. Hablar de la ciudadanía de los indígenas o de categorías específicas de la población que tradicionalmente han estado marginadas $u$ oprimidas (esto puede incluir a las mujeres, a minorías sexuales o religiosas, a grupos de inmigrantes, etc.) implica el reconocimiento de una historia de discriminación y subordinación y un compromiso activo con la reversión de esta situación, reconociendo la inevitable tensión entre los derechos individuales y los derechos colectivos.

Esta tensión plantea otro dilema que tampoco puede encontrar una solución definitiva y en abstracto. Hay dos significados posibles de lo que suele llamarse "derechos colectivos". Los derechos colectivos pueden referirse al derecho de un grupo a limitar la libertad de sus propios miembros en nombre de la solidaridad de grupo o de la pureza cultural: se trata de restricciones internas. Por ejemplo, dirigentes de un grupo religioso que reaccionan negativamente a la decisión de determinados miembros de no seguir las prácticas o las costumbres tradicionales del grupo. Y la noción de "derechos colectivos" puede aludir también al derecho de un grupo a limitar el poder político y económico ejercido sobre él por la sociedad mayor de la que forma parte. Se persigue así asegurar que los recursos y las instituciones de que depende ese grupo en tanto minoría no sean vulnerados por las decisiones de la mayoría: se trata, esta vez, de protecciones externas. Es decir, ese mismo grupo religioso es minoritario en un país cuyo gobierno nacional decide apoyar económicamente a otro grupo religioso al que se siente más afín. Ante ello, seguramente los dirigentes reaccionarán ante el gobierno nacional, no para conseguir una limitación interna sino para protegerse de lo que entenderían como una situación externa injusta y desfavorable.

En las democracias liberales se tiende a aceptar algunas "protecciones externas" para las "minorías" étnicas y otros grupos sociales subordinados pero no se da lugar a las "restricciones internas". Las protecciones externas no entran necesariamente en conflicto con la libertad individual. La mayoría de tales derechos no tiene que ver con la primacía de la comunidad sobre los individuos, sino que se basa en la idea de que la justicia entre grupos exige que a los miembros de grupos diferentes se les concedan derechos diferentes. Por ese camino podríamos pensar en derechos diferenciados o ciudadanía diferenciada en función de la pertenencia a un grupo sin que ello choque con la idea de los derechos individuales universales.

\section{Bibliografía}

Arendt, Hanna (1949). "The rights of man:what are they?" Modern Review, 3/1, verano. (1973). "The origins of totalitarianism." Brace\&World.

Nueva York: Harcourt.

Habermas, Jürgen (1975). Legitimation crisis. Boston: Beacon Press.

Jelin, Elizabeth (1996). "La construcción de la ciudadanía: entre la solidaridad y la responsabilidad." En Jelin, E y Hershberg, E. (eds.). Construir la democracia: derechos humanos, ciudadanía y sociedad en América Latina. Caracas: Nueva Sociedad. Jelin, Elizabeth; Caggiano, Sergio y Mombello, Laura (2011). Por los derechos. Mujeres y hombres en la acción colectiva. Buenos Aires: Nueva Trilce. Kelly, George (1979). "Who needs a theory of citizanship?" Daedalus, 108, n4 Lechner, Norbert (1986). "Los derechos humanos como categoría política." En Ansaldi, Waldo (ed.). La ética de la democracia. Buenos Aires: CLACSO. Lechner, Norbert (1993). "Modernización y modernidad: la búsqueda de ciudadanía." En Centro de Estudios Sociológicos (eds.). Modernización económica, democracia política y democracia social. México: El Colegio de México.

Lefort, Claude (1987). "Los derechos del hombre y el estado benefactor." Vuelta. Julio. Marshall, T.H (1964). Citizenship and social democracy. Nueva York: Doubleday. Offe, Claus (1985). Contradictions of welfare state. Cambridge: Mass MIT Press. Reis, Fabio Wanderley (1983). "Ciudadanía, Estado y mercado. Democracia social y democracia política en el proceso de transformación capitalista." En Centro de Estudios Sociológicos (ed.). Modernización económica, democracia política y democracia social. México: El Colegio de México.

Scott, Joan (1996). Only paradoxes to offer: french feminist and the rights of mna. Cambridge: Harvard University Press.

Van Gunsteren, Herman (1978). "Notes on a theory of citizeship." En Birnbaum, J y Parry, G (eds.). Democracy, consensus and social contract. Londres: Sage. 